\title{
Carious lesions recurrence in children with developmental disabilities: a longitudinal study
}

\section{Lia Silva de CASTILHO(a) (iD Ivana Márcia Alves DINIZ(a) Bruno Pereira dos Reis SANTOS(a) iD Frederico Santos LAGES ${ }^{(b)}$ Alex Júnio Silva da CRUZ(c) iD Mauro Henrique Nogueira Guimarães ABREU(c) (iD)}

\footnotetext{
(a) Universidade Federal de Minas Gerais UFMG, School of Dentistry, Department of Restorative Dentistry, Belo Horizonte, MG, Brazil.

(b) Centro Universitário Newton de Paiva, Dental School, Belo Horizonte, MG, Brazil.

(c) Universidade Federal de Minas Gerais UFMG, School of Dentistry, Department of Social and Preventive Dentistry, Belo Horizonte, MG, Brazil.
}

Declaration of Interests: The authors certify that they have no commercial or associative interest that represents a conflict of interest in connection with the manuscript.

Corresponding Author:

Lia Silva de Castilho

E-mail: liasilvacastilho@gmail.com

https://doi.org/10.1590/1807-3107bor-2021.vol35.0071

Submitted: June 22, 2020

Accepted for publication: October 22, 2020

Last revision: November 30, 2020

\begin{abstract}
This study investigated the factors associated with new carious lesions in one-to five-year-old children with developmental disabilities. This was a retrospective cohort that evaluated 64 dental charts of individuals with caries or fillings in their first dental appointment. The dependent variable was the occurrence of a new carious lesion or restoration. Gender, age, mother's education, sugar consumption, oral hygiene, mouth breathing, reports of xerostomia, gingival status, use of psychotropic drugs, use of asthma drugs, history of asthma, bronchitis, reflux or seizures and having at least one sibling were covariates. Cox proportional hazards regression model was used to estimate the raw and adjusted hazard ratios with their respective 95\% confidence interval. The average time that individuals remained free of dental caries/restoration was 79.49 months (95\%CI: 64.37 to 92.61 ). Increase in sucrose consumption increased the rate of caries recurrence $(\mathrm{HR}=1.16 ; 95 \% \mathrm{CI}: 1.04$ to 1.30$)$. Individuals who had poor oral hygiene had higher rate of new dental caries (HR $=3.88$; $95 \% \mathrm{CI}: 1.22$ to 12.37) compared to those with good oral hygiene. The presence of mouth breathing decreased the rate of recurrence of the disease when compared to the nasal breathing ( $\mathrm{HR}=0.32 ; 95 \% \mathrm{CI}$ : 0.15 to 0.70$)$. Oral health-related behaviors and nasal respiration influenced the rate of dental caries recurrence in individuals with developmental disabilities.
\end{abstract}

Keywords: Developmental Disabilities; Dental Caries; Epidemiology.

\section{Introduction}

Dental caries in both primary and permanent dentitions involves several determinant factors that are mainly divided into biological, socio-economic, environmental, and behavioral. As such, the past experience of dental caries has been considered one of the best predictors of the risk of developing new carious lesions. ${ }^{1,2,3,4,5}$ Other variables are also associated with new dental caries in the literature. Mother's formal education (less than eight years of study), ${ }^{6}$ deficient oral hygiene, frequent intake of sweets and high-sucrose foods, and the use of night bottles are also risk factors for caries incidence. Several prospective studies looked at dental caries in both primary and permanent dentition, but the literature is scarce about the outcome in patients with developmental disabilities.

In a 4-year cohort study, the incidence of dental caries among patients with cerebral palsy who participated in a dental program in Brazil was 
associated with sucrose consumption and having at least one sibling. Patients whose parents or guardians had more years of schooling had fewer carious lesions. ${ }^{7}$ Among individuals who were caries-free at baseline, sucrose intake was the only risk factor for the onset of the disease. ${ }^{8}$ In a retrospective cohort study, where a group of patients with cerebral palsy was compared with groups of patients with Down syndrome, autism spectrum disorder, heart disease, and normal children, the previous experience of the disease was the only risk factor at the age of 6 to 71 months. ${ }^{5}$ Despite evidence that past experience of caries is a risk factor for new lesion development, ${ }^{1,2,3,4,5}$ little is known about the risk factors for new carious lesions in patients who already have dental caries at the first dental appointment in this group of patients.

No longitudinal study was found in the literature investigating risk factors for recurrence of dental caries among children with developmental disabilities. Thus, the goal of this study was to investigate the factors associated with the rate of recurrence of dental caries among a population of 1-to-5-year-old children with developmental disabilities who attended a dental reference service in a large Brazilian city.

\section{Methodology}

\section{Study design}

This retrospective cohort study was based on the information obtained from dental records for people with developmental disabilities in a clinical reference service center in Belo Horizonte, Minas Gerais State, Brazil. Most patients had cerebral palsy. The data collected were for the period from January 1998 to December 2019. The selection was made based on the dental records of children aged from 1 to 5 years, presenting tooth cavities, carious lesions, or lost permanent teeth. This age group was based on two longitudinal studies on the incidence of new caries in patients with disabilities. ${ }^{5,10}$ From a total of 750 dental records, 132 were of individuals who had dental caries at the first consultation with ages ranging from 1 to 33 years. From this total, 68 dental records were of children aged 1 to 5 years. Four records were of single-visit patients and, finally, 64 records were included in this study.

\section{Data collection}

A single trained, and calibrated researcher (BS) (Cohen Kappa $=1.0)$ was in charge of collecting information from the records. A database was created in the Excel Windows program (Microsoft, Redmond, USA) and was reviewed by a different researcher (LSC) with 22 years of experience in oral care for patients with developmental disabilities.

The dependent variable was the time of occurrence (in months) when a new lesion (event/failure) was diagnosed according to World Health Organization criteria, ${ }^{9}$ in subsequent dental appointments. Cases of patients' dental treatment abandonment or death, as well as the absence of new carious lesions or preserved fillings at the end of the monitoring period were censored.

The m component of the decayed, missing, and filled teeth index $(\mathrm{dmft})$ was quantified only when a tooth was indicated for extraction due to caries. If there was uncertainty in determining whether tooth loss was due to natural exfoliation or due to caries, missing teeth were not included in the analysis. No teeth were missing due to agenesis. Due to the patients' high degree of involuntary movements, spasticity, and cognitive impairment, interproximal and periapical radiographic exams were not performed. The follow-up of each patient ranged from 1 to 161 months.

The following covariates were collected: age (in years), gender, maternal education (less than eight years or more than eight years of formal schooling); sucrose intake index (scale), mouth breathing (yes or no), ${ }_{1}^{11}$ changes in gingival color and contour (yes or no), ${ }^{12}$ xerostomia (yes or no), use of psychotropic drugs (yes or no); use of drugs for asthma treatment (yes or no), prior history of asthma (yes or no), prior history of bronchitis (yes or no), having one or more siblings (yes or no), oral hygiene (good, fair or poor), present history of seizures (yes or no), previous history of gastroesophageal reflux (yes or no), prematurity at birth (yes or no), and missing an subsequent appointment for dental consultation (yes or no).

\section{Statistical analysis}

The statistical analysis involved three steps. Initially, a description of all covariates was made by calculating percentages, measures of central 
tendency, and variability. In a second step, the Kaplan-Meier method was used to estimate the mean $(95 \% \mathrm{CI})$ and median survival time (how long the subject was free of a new dental carious lesion). A survival graph was drawn. In a third step, Cox's unadjusted and adjusted models were used to estimate the crude and adjusted hazard ratio - HR (95\% CI), respectively. Each covariate was included separately in the Cox model, and the unadjusted HR $(95 \% \mathrm{CI})$ and $\mathrm{p}$ values were estimated. Covariates with $\mathrm{p}$ values $<0.25$ were included in the final Cox model, where only variables that maintained $p$ values $<0.05$ remained. The statistical analysis was performed using SPSS for Windows software (SPSS Inc., Chicago, USA). Graphical techniques were used to assess the suitability of the final model.

\section{Ethical aspects}

This study was approved by the Ethics Committee on Human Research of Federal University of Minas Gerais under protocol number ETIC 219/03.

\section{Results}

The mean age of subjects was 3.29 years. The average time that individuals remained free of new lesions was 79.49 months (95\% CI 64.37 to 92.61) with median of 50 months (Figure). The sucrose intake index ranged from 2 to 14 with a median of 10. The majority of the individuals was male, had a sibling, and missed an appointment for dental consultation. The presence of comorbidities is a common finding in this group (Table 1). More details on sociodemographic and clinical characteristics are shown in Table 1.

An increase in sucrose consumption increased the rate of caries recurrence $(\mathrm{HR}=1.16$; $95 \% \mathrm{CI}$ : 1.04 to 1.30). Individuals who had poor oral hygiene had increased rate of new dental caries $(\mathrm{HR}=3.88$; 95\%CI: 1.22 to 12.37 ) when compared to individuals with good oral hygiene. The presence of mouth breathing decreased the rate of caries recurrence when compared to nasal breathers ( $\mathrm{HR}=0.32 ; 95 \% \mathrm{CI}$ : 0.15 to $0.70)$. Other variables with $p \leq 0.25$, such as the use of psychotropic drugs, age, and missing appointments were not retained in the final model. The majority

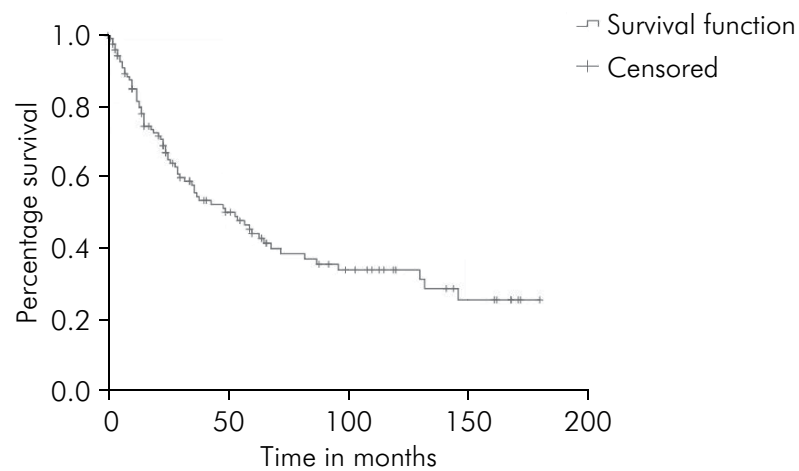

Figure. Survival function of recurrence of cavitated dentin carious lesion and/or restorations among patients with developmental disabilities, age $\geq 5$ years in Belo Horizonte, Brazil, 1998 to 2019.

Table 1. Clinical and sociodemographic characteristics of patients with developmental disabilities and with dental caries at the first appointment, age $\geq 5$ years in Belo Horizonte, Brazil, from 1998 to 2019.

\begin{tabular}{lc}
\hline Variables & $n(\%)$ \\
\hline Prematurity $(\mathrm{n}=56)$ & $25(39.1)$ \\
Have a sibling $(\mathrm{n}=62)$ & $38(59.4)$ \\
Missed dental appointment $(\mathrm{n}=62)$ & $45(70.3)$ \\
Gastroesophageal reflux $(\mathrm{n}=47)$ & $9(14.1)$ \\
Convulsion $(\mathrm{n}=63)$ & $27(42.2)$ \\
Use of psychotropic drugs $(\mathrm{n}=62)$ & $25(39.1)$ \\
Use of drugs for asthma treatment $(\mathrm{n}=62)$ & $5(7.8)$ \\
Previous history of asthma $(\mathrm{n}=49)$ & $5(7.8)$ \\
Bronchitis $(\mathrm{n}=49)$ & $15(23.4)$ \\
Gender $(\mathrm{n}=64)$ & \\
$\quad$ Male & $33(51.6)$ \\
Female & $31(48.4)$ \\
Mother formal education $\leq 8$ years $(\mathrm{n}=61)$ & $19(29.7)$ \\
Oral hygiene $(\mathrm{n}=58)$ & \\
$\quad$ Good & $32(50.0)$ \\
Fair & $19(29.7)$ \\
Poor & $7(10.9)$ \\
Mouth breathing $(\mathrm{n}=63)$ & $36(56.3)$ \\
Xerostomy $(\mathrm{n}=63)$ & $11(17.2)$ \\
Gingivitis $(\mathrm{n}=58)$ & $7(10.9)$ \\
\hline
\end{tabular}

of covariates was not associated with the outcome (Table 2). The median survival time for those with good, fair, and poor oral hygiene was 38.0, 24.0 and 13.0, respectively. The median survival time, in months, for those with and without mouth breathing was 21.0 and 38.0, respectively. 
- Carious lesions recurrence in children with developmental disabilities: a longitudinal study

Table 2. Risk factors for new dental caries lesions among patients with developmental disabilities in Belo Horizonte, Brazil, from 1998 to 2019.

\begin{tabular}{|c|c|c|c|c|}
\hline Variable & Unadjusted HR (95\%Cl) & P value & Adjusted HR $(95 \% \mathrm{Cl})$ & $P$ value \\
\hline \multicolumn{5}{|l|}{ Sex } \\
\hline Male & 1 & \multirow{2}{*}{0.880} & & \\
\hline Female & $0.97(0.63-1.47)$ & & & \\
\hline Age (in years) & $0.87(0.70-1.07)$ & 0.203 & & \\
\hline \multicolumn{5}{|c|}{ Mother formal education (years) } \\
\hline Up to 8 & $0.97(0.91-1.04)$ & \multirow{2}{*}{0.468} & & \\
\hline More than 8 & 1 & & & \\
\hline \multicolumn{5}{|l|}{ Having a sibling } \\
\hline Yes & $1.30(0.65-2.44)$ & \multirow{2}{*}{0.400} & & \\
\hline No & 1 & & & \\
\hline \multicolumn{5}{|c|}{ Missing an appointment } \\
\hline Yes & $2.42(1.10-5.30)$ & \multirow{2}{*}{0.020} & & \\
\hline No & 1 & & & \\
\hline \multicolumn{5}{|l|}{ Prematurity } \\
\hline Yes & $1.29(0.68-2.45)$ & \multirow{2}{*}{0.422} & & \\
\hline No & 1 & & & \\
\hline \multicolumn{5}{|l|}{ Gatroesophageal reflux } \\
\hline Yes & $1.46(0.62-3.43)$ & \multirow{2}{*}{0.370} & & \\
\hline No & 1 & & & \\
\hline \multicolumn{5}{|l|}{ Convulsion } \\
\hline Yes & $0.98(0.53-1.82)$ & \multirow{2}{*}{0.970} & & \\
\hline No & 1 & & & \\
\hline \multicolumn{5}{|c|}{ Use of psychotropic drugs } \\
\hline Yes & $1.51(0.81-2.83)$ & \multirow{2}{*}{0.191} & & \\
\hline No & & & & \\
\hline \multicolumn{5}{|c|}{ Use of drugs for asthma treatment } \\
\hline Yes & $0.99(0.30-3.22)$ & \multirow{2}{*}{0.990} & & \\
\hline No & 1 & & & \\
\hline \multicolumn{5}{|c|}{ Previous history of asthma } \\
\hline Yes & $0.58(0.14-2.45)$ & \multirow{2}{*}{0.464} & & \\
\hline No & 1 & & & \\
\hline \multicolumn{5}{|l|}{ Bronchitis } \\
\hline Yes & $0.74(0.35-1.57)$ & \multirow{2}{*}{0.443} & & \\
\hline No & 1 & & & \\
\hline Oral hygiene & & & & \\
\hline Good & 1 & & 1 & \\
\hline Fair & $1.54(0.76-3.08)$ & 0.223 & $1.04(0.45-2.39)$ & 0.935 \\
\hline Poor & $4.39(1.65-11.66)$ & 0.003 & 3.88 (1.22-12.37) & 0.022 \\
\hline Sucrose intake index & $1.15(1.02-1.30)$ & 0.021 & $1.16(1.04-1.30)$ & 0.008 \\
\hline Mouth breathing & & & & \\
\hline Yes & $0.55(0.30-1.01)$ & ○ी० & $0.32(0.15-0.70)$ & מ \\
\hline No & 1 & 0.005 & 1 & 0.004 \\
\hline Xerostomy & & & & \\
\hline Yes & $1.17(0.52-2.64)$ & ค 700 & & \\
\hline No & 1 & 0.100 & & \\
\hline Gingivitis & & & & \\
\hline Yes & 1.07 (0.41 -2.78) & ค 878 & & \\
\hline No & 1 & $0.8 / 8$ & & \\
\hline
\end{tabular}




\section{Discussion}

In this longitudinal study, the rate of caries recurrence among children with developmental disabilities was assessed. Overall data showed that sucrose consumption, poor oral hygiene, and mouth breathing were the independent variables associated with the rate of recurrence of carious lesions development in the studied patients.

Sucrose consumption has been well described as a risk factor for dental caries in children, ${ }^{1}$ including longitudinal studies with children with developmental disabilities. ${ }^{78}$ In the present study, sucrose consumption was found to increase the rate of new caries. These results are in line with our previous study with patients within the same preventive program but who were free of caries at the first dental visit. ${ }^{8}$ Accordingly, in those patients, sucrose consumption was the only risk factor found for new dental caries. Diet, particularly refined carbohydrates, is known to modulate the dysbiotic scenario, being a determinant factor for carious lesions development. ${ }^{13}$ However, the modification of eating habits is difficult since the parent's food preferences affect those of their children., ${ }^{714}$ Educating parents and caregivers could be an alternative approach to reduce sugar ingestion.

Poor oral hygiene increased the rate of recurrence of dental caries lesions. This result is in line with a previous cross-sectional epidemiological study, where the authors found that the poor oral hygiene habits were associated with dental caries in in children with up to 5 years of age with cerebral palsy. ${ }^{15}$ In a 10-year prospective study conducted in Finland, poor oral hygiene was also detected as a risk factor for the development of the disease at age 3 years. Oral hygiene behavior persists from childhood to puberty ${ }^{1}$ and reinforces the need of additional methods for disease prevention, particularly in special needs communities.

Regarding mouth breathing, the result of the present study is contradictory to the current literature. ${ }^{16,17}$ Herein, mouth breathing was shown to be a protective factor against the recurrence of the disease, but it was not possible to identify the reasons for this association. We hypothesized that mouth breathing may be considered by parents and caregivers as a physical condition that inspires greater care, including oral hygiene.
Noteworthy, the average time individuals remained free of new lesions was 79.49 months, which is lower than that presented in our previous study with caries-free participants at the first dental visit. ${ }^{8}$ Accordingly, our data indicates that the monitoring period should be shortened for patients with developmental disabilities who already present caries experience in the first dental visit, in order to prevent caries recurrence.

We expected that all the other independent variables would have some association with the rate of new dental caries occurrence. This lack of association could be related to the type of study and/or characteristics of the sample. Thus, we recognize that this study had some limitations that we have described previously. ${ }^{8}$ Data were obtained from dental records, which might present biased information. In this reference dental service center, the dental team recalls the children periodically for appointments, but it is not possible to accurately estimate the date of caries appearance and/or restoration. All investigated factors were collected at the first dental visit, which may have been modified over time. Therefore, some variables may differ from those found at baseline. Another limitation was the sample size, which was small because most children aged 1 to 5 years entered the dental program free of caries and this may have influenced the results. Despite a posteriori power calculation showing values greater than $80 \%$ for the covariates in the final model [results not shown], our sample size could have influenced the association results with other covariates.

The present study is one of the few with a methodology that enables the estimation of factors associated with the rate of caries recurrence in patients with developmental deficiencies. This study can help dentists who work with this patient group to plan strategic actions, particularly in relation to health education and dietary guidance, to improve the oral health of patients with developmental deficiencies.

\section{Conclusion}

Oral health-related behaviors and nasal respiration influence the rate of dental caries recurrence in individuals with developmental disabilities. 
- Carious lesions recurrence in children with developmental disabilities: a longitudinal study

\section{References}

1. Mattila ML, Rautava P, Aromaa M, Ojanlatva A, Paunio P, Hyssälä L, et al. Behavioural and demographic factors during early childhood and poor dental health at 10 years of age. Caries Res. 2005 Mar-Apr;39(2):85-91. https://doi.org/10.1159/000083152

2. Vallejos-Sánchez AA, Medina-Solís CE, Casanova-Rosado JF, Maupomé G, Minaya-Sánchez M, Pérez-Olivares S. Caries increment in the permanent dentition of Mexican children in relation to prior caries experience on permanent and primary dentitions. J Dent. 2006 Oct;34(9):709-15. https://doi.org/10.1016/i.jdent.2006.01.003

3. Kassawara AB, Tagliaferro EP, Cortelazzi KL, Ambrosano GM, Assaf AV, Meneghim MC, et al. Epidemiological assessment of predictors of caries increment in 7-10-year-olds: a 2-year cohort study. J Appl Oral Sci. 2010 Mar-Apr;18(2):116-20. https://doi.org/10.1590/S1678-77572010000200004

4. Cabral MB, Mota EL, Cangussu MC, Vianna MI, Floriano FR. Risk factors for caries-free time: longitudinal study in early childhood. Rev Saude Publica. 2017 Dec;51:118-28. https://doi.org/10.11606/S1518-8787.2017051006558

5. Frank M, Keels MA, Quiñonez R, Roberts M, Divaris K. Dental Caries Risk Varies Among Subgroups of Children with Special Health Care needs. Pediatr Dent. 2019 Sep;41(5):378-84.

6. Tagliaferro EP, Pereira AC, Meneghim MC, Ambrosano GM. Assessment of dental caries predictors in a seven-year longitudinal study. J Public Health Dent. 2006;66(3):169-73. https://doi.org/10.1111/j.1752-7325.2006.tb02575.x

7. Ferreira de Camargo MA, Frias AC, Antunes JL. The incidence of dental caries in children and adolescents who have cerebral palsy and are participating in a dental program in Brazil. Spec Care Dentist. 2011 Nov-Dec;31 (6):210-5. https://doi.org/10.1111 /j.1754-4505.2011.00213.xPMID:22070360

8. Brauna AP, Abreu MH, Resende VL, Castilho LS. Risk factors for dental caries in children with developmental disabilities. Braz Oral Res. 2016 June;30(1):79-84. https://doi.org/10.1590/1807-3107BOR-2016.vol30.0079

9. World Health Organization. Oral health surveys: basic methods. 5th ed. Geneva: World Health Organization; 2013.

10. Corrêa-Faria P, Paixão-Gonçalves S, Paiva SM, Pordeus IA. Incidence of dental caries in primary dentition and risk factors: a longitudinal study. Braz Oral Res. 2016 May;30(1):e59. https://doi.org/10.1590/1807-3107BOR-2016.vol30.0059

11. Castilho LS, Abreu MH, Oliveira RB, Silva MES, Resende VL. Factors associated with mouth breathing in children with -developmental -disabilities. Spec Care Dentist. 2016 Mar-Apr;36(2):75-9. https://doi.org/10.1111/scd.12157

12. Lobene RR, Weatherford T, Ross NM, Lamm RA, Menaker L. A modified gingival index for use in clinical trials. Clin Prev Dent. 1986 Jan-Feb;8(1):3-6.

13. Machiulskiene V, Campus G, Carvalho JC, Dige I, Ekstrand KR, Jablonski-Momeni A, et al. Terminology of dental caries and dental caries management: consensus report of a workshop organized by ORCA and Cariology Research Group of IADR. Caries Res. 2020;54(1):7-14. https://doi.org/10.1159/000503309

14. Kim HS, Park J, Ma Y, Im M. What are the barriers at home and school to healthy eating?: overweight/obese child and parent perspectives. J Nurs Res. 2019 Oct;27(5):e48. https://doi.org/10.1097/jnr.0000000000000321

15. Roberto LL, Machado MG, Resende VL, Castilho LS, Abreu MH. Factors associated with dental caries in the primary dentition of children with cerebral palsy. Braz Oral Res. 2012 Sep-Oct;26(5):471-7. https://doi.org/10.1590/S1806-83242012005000018PMID:22892879

16. Ballikaya E, Guciz Dogan B, Onay O, Uzamis Tekcicek M. Oral health status of children with mouth breathing due to adenotonsillar hypertrophy. Int J Pediatr Otorhinolaryngol. 2018 Oct;113:11-5. https://doi.org/10.1016/j.ijporl.2018.07.018

17. Wu L, Chang R, Mu Y, Deng X, Wu F, Zhang S, et al. Association between obesity and dental caries in Chinese children. Caries Res. 2013;47(2):171-6. https://doi.org/10.1159/000344017 